\title{
Renovación generacional mediante la formación para el emprendimiento en la zona cafetera del norte del Tolima
}

\author{
Miguel Ángel Rivera-González ${ }^{\star}$ Edicson Rubiano-Aranzales ${ }^{\star \star}$
}

* Magíster en Administración con énfasis en Finanzas Corporativas, Universidad del Mar. Profesor investigador, Facultad de Contaduría Pública, Universidad Cooperativa de Colombia, Ibagué, Colombia. Correo electrónico: miguel.rivera@campusucc.edu.co

** Especialista en Gerencia de Proyectos, Universidad del Tolima. Profesor, Facultad de Derecho, Universidad Cooperativa de Colombia, Ibagué, Colombia. Correo electrónico: edicson.rubianoa@campusucc.edu.co

Recibido: 10 de octubre del 2014 Aprobado: 7 de noviembre del 2014

Cómo citar este artículo: Rivera-González, M. A. y Rubiano-Aranzales, E. (2014). Renovación generacional mediante la formación para el emprendimiento en la zona cafetera del norte del Tolima. Cooperativismo \& Desarrollo, 22(105), 7-15. doi: http://dx.doi org/10.16925/co.v22i105.1031

\begin{abstract}
Resumen
El proyecto de renovación generacional para la sostenibilidad de la caficultura en el norte del Tolima inicia como una estrategia diseñada por la Cooperativa de Caficultores del Norte del Tolima (Cafinorte), orientada a detener la masiva migración de los jóvenes campesinos a la ciudad. Promueve la participación de la comunidad rural - especialmente de estudiantes- en la construcción y cohesión del tejido social, mediante un proceso de educación y formación en el cual el joven descubre el potencial de oportunidades que le brinda su finca como organización y empresa. El contexto en el cual se desarrolla la investigación se determina por el radio de acción de la cooperativa en los municipios de Fresno - sede principal de Cafinorte-, Herveo, Palocabildo y Falán, ubicados en el departamento del Tolima. La educación y la formación conforman el proceso que determina el emprendimiento, la cultura asociativa y la empresarialidad solidaria, con el apoyo de las escuelas y colegios rurales del área de influencia de la cooperativa, la cual, orientada al cambio de paradigmas aprendidos de sus progenitores, permite que interpreten su realidad y encuentren alternativas posibles que hagan productivas sus fincas.
\end{abstract}

Palabras clave: caficultura, emprendimiento, formación, mentalidad empresarial, relevo generacional.

\section{Generational Renewal through Entrepreneurial Training in the Coffee Zone of Northern} Tolima

\begin{abstract}
The project for generational renewal for the sustainability of coffee culture in northern Tolima began as a strategy designed by the Coffee Growers Cooperative of Northern Tolima (Cooperativa de Caficultores del Norte del Tolima, Cafinorte), aimed at stopping the mass migration of young farmers to the cities. It promotes participation by the rural community, particularly students, in the building and cohesion of the social fabric. It does so through a process of education and training in which young people discover the potential opportunities that their farms can provide as organizations and companies. The context in which the research is carried out is determined by the radius of action of the cooperative in the municipalities of Fresno, where the head office of Cafinorte is located, and in Herveo, Palocabildo and Falán in the department of Tolima. The process for learning entrepreneurship consists of education and training in associative culture and solidarity entrepreneurship with support from the rural schools in the area of influence of the cooperative. The goal is to change paradigms learned from their parents to enable them to interpret their reality and find possible alternatives that would make their farms productive.
\end{abstract}

Keywords: coffee culture, entrepreneurship, training, business mentality, generational relief.

Renovação geracional mediante a formação para o empreendimento na área cafeeira do norte do Tolima

\section{Resumo}

Este projeto de renovação geracional para a sustentabilidade da cafeicultura no norte do Tolima (Colômbia) inicia como uma estratégia desenhada pela Cooperativa de Cafeicultores do Norte do Tolima (Cafinorte), orientada a deter a massiva migração dos jovens camponeses à cidade. Promove a participação da comunidade rural - especialmente de estudantes - na construção e coesão do tecido social por meio de um processo de educação e formação no qual o jovem descobre o potencial de oportunidades que sua fazenda lhe oferece como organização e empresa. O contexto no qual se desenvolve a pesquisa é determinado pelo ráio de ação da cooperativa nos municípios de Fresno (sede principal da Cafinorte), Herveo, Palocabildo e Falán, localizados no estado do Tolima. A educação e a formação conformam o processo que determina o empreendimento, a cultura associativa e a empresalidade solidária, com o apoio das escolas e colégios rurais da área de influência da cooperativa, a qual, orientada à mudança de paradigmas aprendidos de seus progenitores, permite que interpretem sua realidade e encontrem alternativas possíveis que façam produtivas suas propriedades.

Palavras-chave: cafeicultura, empreendimento, formação, mentalidade empresarial, renovação geracional. 


\section{Introducción}

El proceso de expansión de la caficultura en Colombia se puede dividir en dos procesos históricos distintos. El primero va desde su introducción a principios del siglo XIX, cuando el café fue traído desde Venezuela a Norte de Santander, departamento que constituye el epicentro desde donde se difundió la caficultura al resto del país, primero a Santander y después a Cundinamarca y Antioquia. Este primer periodo se caracterizó principalmente por el auge de las haciendas y las grandes explotaciones. Sin embargo, la hacienda no era el lugar desde donde Colombia se convertiría en un país monoexportador de café, así como no sería la base del desarrollo cafetero sino su precursora, a lo largo del siglo XIX y en todas sus variaciones regionales. La hacienda nunca dominará el paisaje cafetero colombiano, por el contrario, se desarrollará en medio de una mezcla de contradicciones sociales, económicas y políticas que la acabarán para la tercera década del siglo xx.

El segundo momento expansivo se relaciona con la difusión de la caficultura en los territorios de colonización antioqueña, principalmente en los actuales departamentos de Caldas, Risaralda y Quindío, lugares en donde comienza a explotarse comercialmente el cultivo desde principios del siglo xx. Tal fue el impacto del cultivo en esta zona del país, conformada por estos tres departamentos, que después se conocería como el "Eje Cafetero". Esta segunda expansión cafetera se caracteriza por las explotaciones medianas y pequeñas de tipo familiar, las cuales a pesar de las múltiples crisis se mantienen hasta hoy (Gil-García, 2006).

El crecimiento de la producción se concentró en el Viejo Caldas, el sur de Antioquia, el norte del Tolima y el norte del Valle del Cauca. En los inicios de la colonización se desarrolló en estas zonas una agricultura de roza y quema ${ }^{1}$, complementada por actividades comerciales como el engorde de cerdos, la guaquería y la explotación del caucho (Ocampo, 1989). La economía cafetera comenzaría a desarrollarse y consolidarse casi una década después del establecimiento de las primeras parcelas. El café no es un cultivo que se adapte adecuadamente a las condiciones de colonización temprana, dado que involucra una considerable inversión

\footnotetext{
1 En este sistema típico de las zonas de colonización, la tierra permanecía inactiva durante largos periodos de tiempo mientras recuperaba su fertilidad. En este sentido, la introducción de la caficultura dio paso a un uso intensivo del suelo que permitía incrementar su producción comercializable.
}

monetaria y su rendimiento es de carácter tardío (por lo menos cinco años después de la siembra). A estas condiciones se suma el hecho de que las zonas de colonización no contaban con la infraestructura necesaria para su trasporte y comercialización. El café tuvo que esperar a que se establecieran las comunidades de colonos con su agricultura de subsistencia (maíz, fríjol, plátano, yuca), y a que mejoraran los caminos de herradura por donde salían los cerdos de engorde para abastecimiento de ciudades lejanas como Medellín y Bogotá (Palacios, 2002). El cultivo de grano se expandió rápidamente en las pequeñas y medianas propiedades que se habían desarrollado en la región, gracias a un largo proceso de lucha por la tierra de los colonizadores contra los adjudicatarios de baldíos, con el apoyo de las élites comerciales de Medellín y después de Manizales (Gil-García, 2006).

Según datos estadísticos del Comité de Cafeteros Departamental, el Tolima en el 2013 produjo 1284000 sacos de café tipo exportación de 60 kilos. Se sostienen más de 60 mil productores en 38 de los 47 municipios del departamento. Están registradas en café 118 mil hectáreas, cuando en el 2005 existían 108 mil. El sector cafetero en el Tolima produce unos 86 mil cargos directos y, entre directos e indirectos, son alrededor de 187 mil empleos generados (Arroyo, 2014). Los municipios a la vanguardia en el departamento del Tolima son Planadas, Líbano, Ibagué y Fresno.

El municipio de Fresno se encuentra situado en el norte del departamento del Tolima, posee un clima templado, agradable y saludable. Cuenta con el atractivo de presentar un clima cálido y plano a tan solo 30 minutos de viaje. A hora y media de viaje vía Manizales, tiene el clima glacial del Nevado del Ruiz, también gran atractivo turístico del país. Las actividades económicas son la agricultura, representada en una amplia producción de aguacates, café, caña de azuzar y ganadería de engorde. El café, a pesar de las vicisitudes que ha tenido su cultivo, ha jugado un papel importante durante toda la historia del municipio. Hoy en día, sigue siendo motor de desarrollo, lo cual le ha permitido a Fresno tomar un liderazgo regional. En este sentido vale la pena resaltar la existencia de unas organizaciones que promueven esta actividad, tales como el Comité de $\mathrm{Ca}$ feteros, la alcaldía municipal con sus proyectos y programas en la producción cafetera, y Cafinorte.

La renovación generacional para la sostenibilidad de la caficultura en el norte del Tolima es un proyecto diseñado por Cafinorte. Está orientada a detener la masiva migración de los jóvenes campesinos a la ciudad, y promueve la participación de la comunidad rural en la 
construcción y cohesión del tejido social. Esto mediante un proceso educativo y formativo, en el cual el joven descubre el potencial de oportunidades que le brinda su finca como organización y empresa. Se soporta en la Ley 1622 del 2013, en su artículo 5, en el cual se denomina joven a toda persona entre 14 y 28 años cumplidos. De igual forma, la Ley 79 de 1988, capítulo tercero, artículo 21, numeral 1, dice: "Los menores que hayan cumplido 14 años de edad" (Ley 79 de 1988). Así como la Ley 454 de 1998, por medio de la cual se determina la economía solidaria en Colombia.

El contexto en el cual se desarrolla la investigación tiene como eje central de operaciones el municipio de Fresno, dada su posición estratégica con respecto a los demás municipios del radio de acción de la cooperativa, y en razón a que allí se encuentra la sede principal de Cafinorte. Cuenta con una comunidad que agrupa a más de 7000 familias cafeteras, extensiones menores a 5 hectáreas y más del 70\% de propietarios en edades entre 55 y 80 años (Cafinorte, 2012).

Resulta urgente iniciar un proceso de formación sobre empresarialidad asociativa cafetera con jóvenes, hijos o nietos de estos productores, el cual cuente con el apoyo de las escuelas y colegios rurales del área de influencia de la cooperativa. Esta formación debe estar orientada al cambio de paradigmas aprendidos de sus progenitores, de manera que interpreten su realidad y encuentren alternativas posibles a través del emprendimiento y la empresarialidad en la producción y comercialización del café. Esto como un propósito al cambio de la cultura finca-empresa.

\section{Desarrollo de los temas}

\section{Educación y formación}

La educación es motor principal de la cooperación, un proceso permanente que si bien conduce a la organización al éxito, trasciende a la comunidad y a su propio desarrollo (Silva, 2008). Según Kant, tan solo a través de la educación puede llegar el hombre a ser hombre, el hombre no es más que lo que la educación hace de él.

Vale la pena poner de manifiesto que la educación ha sido un propósito constante en todas las culturas y sociedades. Cada época genera cuestionamientos sobre los contenidos y la forma como debe impartirse, según la formación de hombres y mujeres, y en concordancia, claro está, con el perfil y los resultados que se esperan de cada proceso en particular (Jaime, 2007).
El proyecto de conexión o relevo generacional implica la transformación de la comunidad, en especial de los jóvenes, con propósitos de desarrollos sostenibles y comunitarios en la construcción de región, de colectividad, emprendimiento y empresarialidad. La educación y formación son dos referentes muy importantes que determinan en la competencia el saber-hacer, lo cual identifica el conocimiento-destreza.

La educación es una característica propia y un valor implícito que se debe fortalecer, promover y mantener en toda situación, en especial cuando se tiende a crecer y desarrollarse. Se educa y se forma a los individuos para permitirles mayores herramientas de gestión social y económica, involucrándolos en la dinámica empresarial, con el fin de conocer su entorno y pensar continuamente en nuevas soluciones que permitan el mejoramiento progresivo de la calidad de vida de las personas y comunidades; en síntesis, se educa para cumplir con el propósito de mantener un desarrollo sostenible e integrado en la construcción de tejido social, al tiempo que se enfoca hacia la competitividad, la productividad y la globalización. En propósitos de emprendimiento y empresarialidad, la educación busca criterios firmes, a fin de cumplir con las responsabilidades de las personas que conforman la colectividad, así como para comprender las necesidades, tanto internas como externas, y contribuir en la generación y aplicación de políticas que permitan construir sociedad a partir de las personas. Estas, más allá de las directrices del mercado, constituyen el objetivo, y por ello los procesos de educación y capacitación deben estar orientados a su realización, crecimiento y desarrollo dentro de la sociedad. Todo esto a partir de la solidaridad y la cooperación como elementos centrales del modelo cooperativo y su estilo particular en la autogestión, lo cual implica madurez empresarial y asociativa.

En la última década, pero especialmente en los últimos años, se ha identificado un vacío en la educación y formación de nuevas generaciones en cultura asociativa y cafetera. Hoy fácilmente se observa cómo los líderes con visión social y empresarial van desapareciendo poco a poco y el reemplazo no está presente para continuar con ese trabajo. La formación de esa nueva base empresarial es tan urgente, que se requiere de métodos que hagan el proceso en corto tiempo, de modo que se logre formar dirigentes capaces de enfrentar los nuevos retos de la caficultura tolimense, y así evitar el fenómeno de migración de los jóvenes a la ciudad. Así, se facilitan los medios para el desarrollo del amor y la identidad con su tierra y región. 
A través de la educación, el proyecto hace del emprendimiento y la empresarialidad solidaria un esfuerzo permanente en la construcción del conocimiento, la formación y cultura asociativa, de manera que sean elementos importantes en el desarrollo rural y agropecuario. Al concebir el cultivo de café como propósito fundamental en el desarrollo socioeconómico, al fomentar fuentes de empleo y trabajo para la población de niños y jóvenes, resulta necesario diseñar un plan que aborde estas dificultades desde las aulas de clase de las escuelas y colegios rurales, enmarcados en procesos asociativos y que propendan hacia el bienestar de toda la comunidad del radio de acción de Cafinorte.

La iniciativa de la educación solidaria busca consolidar el liderazgo, el trabajo en equipo, la motivación y comunicación, aspectos relevantes de la dirección, procesos de formación social y económica, así como la oportunidad para dar soluciones a la inclusión laboral del radio de acción de Cafinorte, la cual involucra los municipios de Fresno, Herveo, Palocabildo y Falán.

Una de las preocupaciones del gremio cafetero es el nivel educativo de los productores y sus familias, lo cual genera en el sector escasa participación de los jóvenes en la continuidad. Esto amenaza la sostenibilidad de la producción de café en la región, como es el caso de dichos municipios y otras zonas cafeteras del departamento. Allí se está presentando a través del tiempo la misma problemática, relacionada con escasa formación asociativa y empresarial cooperativa a las nuevas generaciones, lo cual haría sostenible la caficultura en la región.

Como lo mencionó Benjamín Franklin (17061790), "Dime y lo olvido, enséñame y lo recuerdo, involúcrameylo aprendo" (citado en Blanchardy MilesiFerretti, 2009). De esta manera, se aborda de lleno el tema, ya que para aprender colaborativamente el sujeto debe involucrarse en la tarea a realizar. Deutsch (1949) define el aprendizaje cooperativo como el que se da en una situación de interacción cooperativa en el medio educativo: el sujeto alcanza su objetivo si, y solo si, los otros sujetos también alcanzan los suyos. En otros tipos de aprendizaje el individuo alcanza sus objetivos solo si los demás no alcanzan los suyos (competitivo); en el aprendizaje individualista no hay relación entre los individuos que forman el grupo clase en lo concerniente a los objetivos a alcanzar (Deutsch, 1949).

La práctica y la investigación sobre las relaciones interpersonales y de cooperación en el aula tienen su origen en dos líneas históricas de pensamiento. Por un lado, los trabajos de Dewey (1989) ponen de manifiesto, tanto los aspectos sociales implicados en el proceso de enseñanza y aprendizaje, como la incidencia que tiene la institución educativa en la preparación de los individuos para la vida democrática a través de los procesos de cooperación en el aula. Por otro, las aportaciones realizadas por Lewin (1935), desde la teoría de campo, proponen su modelo sobre la motivación de tal manera que las ideas vertidas en estos trabajos condujeron a realizar una extensión de las mismas al campo de las relaciones interpersonales, permitiéndoles conceptuar tres tipos de relaciones sociales que se pueden establecer en el contexto educativo: cooperación, competición e individualización (Deutsch, 1949).

Los referentes teóricos en la economía solidaria, según Razeto (1998), son el fundamento al paradigma social y solidario de América latina. Desde esta teoría, Soto (2006) realiza, en su tesis doctoral de economía, un análisis de la forma de ver la economía solidaria desde diferentes perspectivas: social y solidaria. En otro punto de vista, Sánchez (2006) considera que la economía solidaria en América Latina se fortalece, lastimosamente, desde el paradigma de la pobreza y marginación, vinculado con el desempleo que afronta la sociedad latinoamericana. La perspectiva solidaria muy pocas veces es reconocida como proyecto de vida que se erige en propuestas de cambio sobre la forma de organizar la sociedad posindustrial. Indudablemente, esto genera nuevos retos, entre los cuales se destaca construir una comunidad en conexión generacional a través del trabajo asociativo.

Arruda plantea: "La economía solidaria es una forma ética recíproca y cooperativa de consumir, producir, intercambiar, financiar, comunicar, educar y desarrollarse que promueve un nuevo modelo de pensar y vivir" (citado en Calderón y Arenas, 2011).

\section{Mentalidad empresarial}

El nuevo siglo se caracteriza por una profunda transformación social, empresarial y tecnológica, la cual está marcando cambios sustanciales en el campo laboral, tanto en las organizaciones como en los modos de vida. Desde enfoques alternativos al sistema tradicional de crear empresas, se vienen construyendo nuevas miradas para empresas del futuro. Esta empresa del futuro estaría conformada por una comunidad de sujetos presentes que se autorrealiza a partir del trabajo, en la cual cada uno participaría de forma democrática en la toma de decisiones y en los excedentes, y cuyo tamaño siempre estaría limitado a su capacidad de funcionar como 
comunidad. La productividad se daría a nivel humano, mejorando la calidad de vida de las personas y la comunidad en general.

Esta nueva visión de organización empresarial necesita con urgencia la formación de personas comprometidas con su autorrealización en el marco del bienestar social, con autoaprendizaje continuo, creativo, de iniciativa y capacidad para el trabajo en equipo. Los nuevos esquemas de gerencia empresarial requieren de una nueva forma de organización empresarial que fomenten la innovación, la creatividad y la flexibilidad funcional, a fin de hacer frente a los cambios en el mercado. Para lograr esto, se requieren nuevas formas de construir sociedad, una gran sensibilidad con el entorno, el establecimiento de lazos de solidaridad, el respeto por los derechos humanos (Dansocial, 2006a), el fortalecimiento de tejido y cohesión social, el respeto al medio ambiente y biodiversidad, así como la compresión mutua.

El emprendimiento es un término poliédrico, directamente relacionado con la acción de la persona. En este sentido, se puede entender como el conjunto de actitudes y conductas que dan lugar a un determinado perfil personal, orientado hacia la autoconfianza, la creatividad, la capacidad de innovación, el sentido de responsabilidad y el manejo del riesgo. El emprendimiento como opción de vida lo realizan personas que poseen habilidades de fácil comunicación, capacidad de liderazgo y actitud positiva para identificar ideas y oportunidades, las cuales analizan tanto los factores exógenos (económicos, sociales, ambientales y políticos), como los endógenos (capacidad de disponer de personas así como de recursos materiales y financieros). La acción emprendedora está orientada al logro de objetivos mediante la puesta en marcha de un sistema organizado de relaciones interpersonales y combinación de recursos (Ramos y Bayter, 2012).

Esta acción emprendedora se puede hacer a título individual o formando parte de un grupo con o sin estructura. Se desarrolla en diversos ámbitos, tales como: a) el emprendimiento empresarial, siendo la principal motivación de sus acciones e iniciativas de carácter económico; b) el emprendimiento social, se propone dar respuesta a necesidades sociales, promueve y sostiene valores, y sus conocimientos, capacidades y recursos los ponen al servicio de la sociedad; y c) emprendimiento público. Es una iniciativa con motivación fundamentalmente política, se intenta trasladar la cultura de la empresa al sector público (Moriano, 2005).
Generar riqueza es posible si se consolida la capacidad productiva, se propicia una mayor dinámica económica y se fortalece la iniciativa privada y la capacidad emprendedora de las personas. En otras palabras, si se realizan las acciones contundentes dirigidas a que haya más y mejores empresas. Estas cumplen un rol muy importante dentro del contexto del desarrollo económico y social, pues además de ser un vehículo ideal para generar riqueza, contribuyen en los siguientes aspectos:

- Generar empleo.

- Son un espacio ideal para que las personas tengan acceso al conocimiento y al aprendizaje permanente, por lo que ayudan a la formación del capital humano.

- Producen y comercializan los bienes y servicios que la comunidad requiere.

- Compiten, se exigen y siempre buscan ser mejores para ganar la preferencia del mercado, lo cual beneficia a los consumidores.

- Innovan, hacen desarrollo tecnológico o apropian tecnologías, de manera que aportan al mejoramiento de las condiciones competitivas frente a otras regiones y países del mundo.

- Facilitan la conectividad de las regiones y del país con el mundo globalizado.

- Contribuyen al bienestar colectivo en la medida en que asumen su responsabilidad y pagan tributos a los entes estatales.

- Ayudan a distribuir de manera más equitativa las oportunidades y los ingresos entre las personas o comunidad (Dansocial, 2006b).

El emprendimiento solidario será toda acción colectiva que busca de manera alternativa desarrollar elementos nuevos, los cuales ayuden a la evolución de la comunidad, pensando globalmente y actuando localmente; en otras palabras, siendo socialmente competentes.

El emprendimiento solidario es un espacio de acción orientada por individuos, familias, comunidades y colectivos de diferentes tipos que se mueven por arreglos voluntarios y actúan haciendo transacciones entre la utilidad material y los valores de solidaridad, cooperación y autogestión. Este tipo de emprendimiento genera sociedad, excedentes económicos y valores de uso para satisfacer necesidades de los mismos productores o de sus comunidades, y de esta manera volverse socialmente competentes (Dansocial, 2006a). 
El desarrollo del espíritu emprendedor requiere de un cambio de mentalidad que permita a las organizaciones realizar proyectos por cuenta propia, sin que los individuos piensen en ser empleados y recibir un salario como única alternativa. Con el fin de emprender proyectos productivos es necesario que las personas aprendan a gerenciar su propio conocimiento, hacer cosas por sí mismas y administrarlas como parte de su proyecto de vida (Dansocial, 2007).

Esto demuestra cómo es necesario asumir un tratamiento multidisciplinario del emprendimiento para comprenderlo de forma exacta (Tobón, 2001). El ciclo del emprendimiento tiene cuatro fases: exposición, necesidad, riesgo y satisfacción (figura 1).

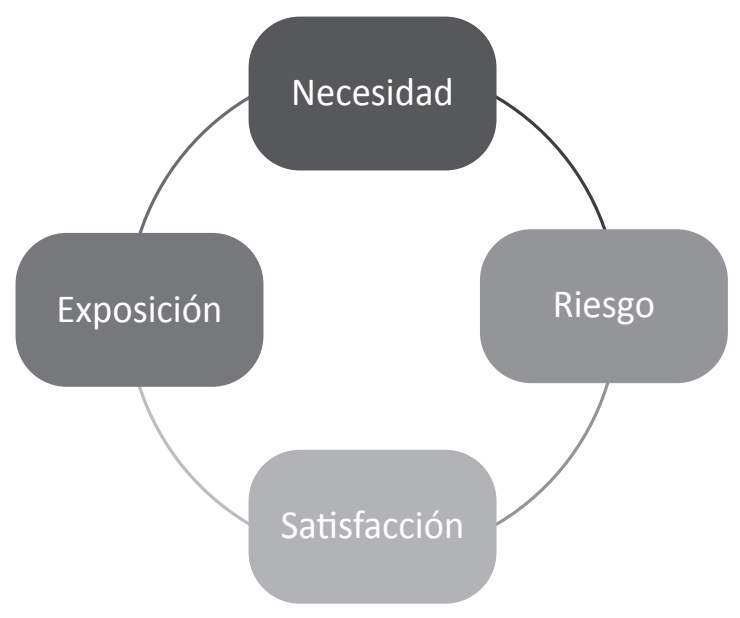

Figura 1. Ciclo del emprendimiento.

\section{Las características del emprendedor}

- El emprendedor se caracteriza por ser impaciente, autónomo, dispuesto al cambio, a asumir riesgos, es decidido, flexible, persistente, tiene la motivación al logro y confía en sí mismo.

- La conducta y actitud del emprendedor se manifiesta en que es responsable, eficiente, busca información, es comprometido por su trabajo, se preocupa por la imagen de sus productos, busca tener buena relación con sus empleados y el medio ambiente.

- En cuanto a las capacidades intelectuales del emprendedor, este se presenta como una persona creativa, orientado a metas concretas, capaz de resolver problemas, de planificar, de detectar y actuar en las oportunidades, de reconocer sus propias limitaciones.
- Entre las habilidades y talentos del emprendedor se encuentran la capacidad de liderazgo, de persuasión, el uso de estrategias de influencia y su carácter asertivo.

- Conocimientos específicos: experiencias o habilidades en el área de finanzas, administrativos, contables, de mercadeo y conocimientos del negocio (Dansocial, 2006a).

\section{Características del pensamiento emprendedor}

- Buscan apasionadamente nuevas oportunidades: están siempre alertas y dispuestos a convertir un cambio en una oportunidad de negocios.

- Son enormemente disciplinados: se aseguran de actuar sobre las oportunidades. La mayoría llevan un tipo de inventario o registro de oportunidades no explotadas.

- Solo persiguen las mejores oportunidades: evitan desgastarse en ideas inútiles o muy sofisticadas para su entorno.

- Se concentran en la ejecución: la gente con pensamiento emprendedor ejecuta, no pierde tiempo analizando ideas que no llevará a la práctica. Pese a esto, es capaz de adaptarse y cambiar de dirección para seguir y explotar una verdadera oportunidad.

- Hace que cada uno se comprometa en lo que sabe y domina: involucran a mucha gente dentro y fuera de la organización en la búsqueda de una oportunidad. No trabajan solos; crean y sostienen redes de relaciones aprovechando la mayor parte de los recursos que la gente tiene para ofrecer, mientras la ayudan a lograr sus objetivos personales y laborales (MacMillan, 2001).

\section{Empresarialidad solidaria}

Se entiende por empresarialidad la capacidad de los individuos de crear empresas. Este proceso se puede clasificar en varias etapas: la identificación de la idea, su validación, el acceso y la organización de recursos, la negociación, el nacimiento y la supervivencia.

Cuando se habla del emprendimiento solidario como una acción colectiva, es importante referirnos al concepto de empresarialidad solidaria, ya que el segundo paso para generar ideas de negocios solidarios es la empresa, en todo tipo de emprendimiento cuya característica de base apunta a trabajar con fuerza en lo solidario. Es decir, ideas creadas con el propósito de 
funcionar sobre principios democráticos plenos e integrales, tanto en lo político como en lo económico, tanto en lo privado como en lo público, operando integralmente como empresa a través de procesos de autogestión.

La autogestión es el instrumento primordial para la toma de decisiones, a partir del cual se llega a acuerdos y se establecen acciones y mecanismos de evaluación de todo orden que garanticen la participación activa de todos los miembros del grupo involucrado, tanto de forma individual como colectiva. Es el pilar sobre el cual irá la dinámica que caracteriza el emprendimiento solidario.

Las características de la economía social y solidaria se dan en la economía de la comunidad o economía de los asuntos colectivos, en la medida en que los objetivos y realizaciones prácticas son sociales. Su interés se centra en la creación de nuevas formas empresariales que, sin limitarse a una sola forma jurídica, abre caminos diferentes y libres de obstáculos para ejercer la gestión económica en igualdad de condiciones legales, pero en inmejorables competencias en cuanto a resultados y respuestas a las expectativas de los asociados.

Los postulados de la empresarialidad solidaria tienen características y condiciones que conjugan la emoción, el sentimiento y la razón, a través de los siguientes postulados:

- Ausencia del ánimo de lucro.

- Democracia.

- Propiedad social.

- Sostenibilidad.

- Productividad.

- Redistribución justa al trabajo.

- Seguridad y desarrollo social (Dansocial, 2006a).

\section{Proceso académico}

Con la ejecución de esta investigación, la zona cafetera del norte del Tolima - específicamente los municipios de Fresno, Herveo, Palocabildo y Falán - fortalecerá su economía a través del talento humano con formación asociativa y empresarial, vinculado a la cooperativa de caficultores Cafinorte. Los beneficiados, con capacidad en el liderazgo, serán gestores del desarrollo y sostenibilidad de la caficultura y estarán calificados para expandir el trabajo comunitario, asumiendo compromisos con su región, entendiendo la institucionalidad cafetera como una forma de vida, forjadora de sociedad, territorios animados y prósperos, constructores de riqueza, conservadores de la naturaleza, del medio ambiente y promotores de convivencia y paz.

Por otra parte, en el proceso formativo se pretende transformar la cultura de cada participante, en cuanto a la importancia que tiene el actuar con compromiso, identidad, fidelidad y lealtad frente a su comunidad y la institucionalidad cafetera en general, solucionando sus necesidades básicas y propiciando el crecimiento económico local y regional.

Por lo tanto, atender esta problemática a corto plazo es una prioridad. De lo contario, aumentaría la caída en la producción de café, la cual en los últimos dos años ha estado por encima del 20\% (FNC, 2010). Esta situación ha puesto en estado de alerta a todas las autoridades del Gremio Cafetero y al Gobierno nacional.

Si se tiene en cuenta que el proyecto de investigación se desarrolla en tres etapas, y cada etapa en un año, al final de las tres etapas se tendrían 300 jóvenes líderes empresariales de los cuatro municipios, con capacidad para dirigir social y económicamente la organización.

\section{Método}

La investigación es formativa, con metodología investigación-acción participativa (IAP). Estructuración teórica de la información y su generalización, diseño e implementación de un plan de acción, evaluación de la acción realizada y verificación en espiral del proceso total. Se soporta en las teorías de Fals Borda (1970), cuyo "interés fue la educación popular, los problemas agrarios y la crítica al reformismo y el cooperativismo".

Según los postulados de los padres del cooperativismo, Robert Owen, Charles Fourier y M. M. Coady, entre otros, se diseñaron los diferentes módulos de intervención, en conformidad con el pensamiento y aplicación del concepto empresarial cooperativo a partir de la educación de adultos. Este será el punto de partida para realizar la integración académica con los jóvenes.

\section{Resultados esperados}

\section{Proyecciones}

Se proyecta involucrar a 100 niños y jóvenes, en edades entre 10 a 14 y 14 a 28 años, así como a sus progenitores como actores del proyecto. 


\section{En lo social}

Se espera aportar a la reducción de los niveles de migración de los jóvenes a las ciudades y a la sostenibilidad de la empresarialidad cafetera.

\section{En lo educativo}

Se busca construir cultura asociativa y empresarial en las nuevas generaciones, a partir de la formación orientada al fortalecimiento de la convivencia y la paz de las comunidades, con base en los principios y valores del cooperativismo.

\section{En lo cultural}

El objetivo es despertar interés en las nuevas generaciones por desarrollar identidad y amor por su región, buscando mantener la sostenibilidad a través de la conservación del medioambiente.

\section{Proyección e investigación}

Se pretende motivar e involucrar a los estudiantes en el proceso de investigación local y regional. En cada institución educativa rural seleccionada para el desarrollo del proyecto, se constituirá una estructura cooperativa con sus estudiantes con el fin de desarrollar el proceso didáctico empresarial cooperativo.

\section{Conclusiones}

La educación y la formación para el emprendimiento empresarial dirigida a niños y jóvenes del radio de acción de la cooperativa Cafinorte tiene fundamentos claros en movilidad comunitaria, transformación de cultura, apego a la construcción de región, desarrollo e innovación en la construcción del tejido y la cohesión social y económica. La formación y la cultura asociativa solidaria son elementos de vital importancia en la región, donde las fuentes de empleo son escasas y las existentes no ofrecen espacios para la población adolescente. Por tanto, diseñar una estructura que aborde estas dificultades es esencial, a fin de que - desde las aulas de clase - se puedan aportar y crear soluciones a los diferentes problemas socioeconómicos. Este proceso tiene como finalidad última el progreso permanente de la región, de la comunidad y de cada individuo residente en ella.
Trabajar por la construcción y el fortalecimiento del capital social a través de niños y jóvenes, es decir, constituir y fortalecer actores locales en la región, genera confianza entre ellos, fortalece la asociatividad y genera acciones conjuntas que permitan una mayor articulación. Construir familiaridad es un elemento clave en el proyecto, y esto es posible cuando se generan las condiciones que propicien el reconocimiento entre las personas por el respeto mutuo, de ser capaces de resolver las diferencias en términos fraternales y construir procesos de desarrollo que dignifiquen lo comunitario.

La capacitación debe generar las competencias necesarias para su consideración, tanto internas como externas, y deben reflejarse en lideres empoderados con un alto sentido de pertenecía, conscientes de sus objetivos como emprendedores y con una visión de futuro colectivo. Desde esta concepción, el fortalecimiento no debe limitase a jornadas de capacitación, por el contrario, se deben crear escenarios, en los cuales los actores pongan en práctica sus aprendizajes y avances progresivamente hacia el logro de sus objetivos. De igual manera, se promuevan sinergias que propendan hacia la articulación en las dinámicas locales del desarrollo. La apuesta hacia un propósito colectivo y la superación del interés individual suponen grandes retos del emprendimiento solidario. En ese proceso, los niños y jóvenes desarrollarán una estrategia que les permitirá como líderes mejorar los canales de comunicación, visibilizar y potencializar nuevos liderazgos, identificar espacios de gestión, concertar un plan de trabajo para la acción, y en última instancia la consolidación como organización social y económica.

Solo en la medida en que los actores sean conscientes de su papel fundamental en el desarrollo, los procesos de fortalecimiento comunitario pasarán de la teoría a la práctica, y se generarán escenarios de participación política que promuevan un bienestar y, por ende, una mejor calidad de vida para toda la comunidad. Einstein sostuvo que no es posible resolver los problemas del presente con la misma mentalidad con la que fueron creados.

\section{Referencias}

Arroyo, C. C. (27 de febrero de 2014). Un 5\% crecería producción cafetera del Tolima este año. En El Nuevo Día. Disponible en http://www.elnuevodia.com.co/nuevodia/actualidad/economica/211404-un-5-creceria-produccion-cafetera-del-tolima-este-ano 
Blanchard, O. y Milesi-Ferretti, G. (2009). Global Imbalances: In Midstream? IMF Staff position: Note 09/29. International Monetary Fund. Disponible en: http://www. imf.org/external/pubs/ft/spn/2009/spn0929.pdf

Cafinorte. (2012). Balance Social. Fresno.

Calderon, A. y Arenas, C. (2011). La educación cooperativa y solidaria como proyecto de vida de los jovenes adolecentes sisbenizados de las instituciones educativas en Barrancabermeja. Cooperativismo y Desarrollo, 1(99), 177-178.

Congreso de Colombia. (Abril 29 de 2013). Ley 1622 del 2013. Por medio de la cual se expide el estatuto de ciudadanía juvenil y se dictan otras disposiciones. Do N. ${ }^{\circ} 48776$.

Congreso de Colombia. (Diciembre 23 de 1988). Ley 79 de 1988. Por la cual se actualiza la Legislación Cooperativa. Do N. ${ }^{\circ} 38648$.

Congreso de Colombia. (Agosto 4 de 1998). Ley 454 de 1998. Por la cual se determina el marco conceptual que regula la economía solidaria, se transforma el Departamento Administrativo Nacional de Cooperativas en el Departamento Nacional de la Economía Solidaria, se crea la Superintendencia de la Economía Solidaria, se crea el Fondo de Garantías para las Cooperativas Financieras y de Ahorro y Crédito, se dictan normas sobre la actividad financiera de las entidades de naturaleza cooperativa y se expiden otras disposiciones. Do N. ${ }^{\circ} 43357$.

Dansocial. (2006a). Curso básico de economía solidaria con énfasis en cooperativas de trabajo asociado. Bogotá: Dansocial.

Dansocial. (2006b). Emprendimiento solidario con perspectiva de género. Bogotá: Dansocial.

Dansocial. (2007). Curso básico de cooperativismo con enfoque de género. Bogotá: Dansocial.

Deutsch, M. (1949). Cooperation and Competition. Washington: Human Relations.

Dewey, J. (1989). A pedagogical experiment. Southern Illinois University Press: Carbonale.

Fals Borda, O. (1970). Educación polular y alternativa. Bogotá: La Rosca.
Federación Nacional de Cafeteros de Colombia. [FNCC]. (2010). Comportamiento de la industria cafetera colombiana 2010. Disponible en: http://www.federaciondecafeteros.org/static/files/2010_Comportamiento.pdf

Gil-García, L. C. (2006). Historia de la caficultura en Colombia. Armenia: faEs.

Jaime, M. D. (2007). Plan nacional decenal de educación para el sector de economía solidaria 2006-2016. Bucaramanga: Universidad Cooperativa de Colombia.

Lewin, K. (1935). A Dynamic Theory of Personality. New York: McGraw-Hill.

Lippit, R. (1947). Human Resource Development Associates Professional Development. Milford.

MacMillan, I. (2001). El pensamiento emprendedor: las características. Massachusetts: Harvard.

Moriano, J. (2005). El perfil psicosocial del emprendedor. Madrid: Consejo Económico y Social.

Ocampo, L. A. (1989). Ciclo cafetero y comportamiento macroeconómico en Colombia. Bogotá: Fedesarrollo.

Palacios, M. (2002). El café en Colombia, 1850-1970: una historia económica, social y política (3a ed.). Bogotá: Planeta.

Ramos, F. S. y Bayter, L. O. (2012). Emprendimiento y economía social, oportunidades y efectos en una sociedad en transformación. CIRIEC- España, 75, 129-151.

Razeto, L. (1998). Economía de solidaridad y mercado democratico. Bilbao: Anuario de Estudios Cooperativos.

Sánchez, A. (2006). Análisis crítico de la estructura organizacional en las OFCC. Recuperado de: http://www. diss.fu-berlin.de/diss/servlets/MCRFileNodeServlet/ FUDISS_derivate_000000001836/01_Thesenpapier. pdf?hosts $=$

Silva, J. (2008). El valor de la educación cooperativa. Colombia Cooperativa, 6, 6.

Soto, M. C. (2006). Financiera rural, influencia en dispersoras e intermediarios financieros rurales zona centro del esado de Veracruz. (Tesis doctoral). México, Universidad Nacional Autónoma de México. Recuperada de http:// www.eumed.net/tesis-doctorales/2009/mcsi/indice.htm

Tobón, S. (2001). Aprender a emprender un enfoque curricular. Mexico: FUNORIE. 